정규논문 (Regular Paper)

방송공학회논문지 제18권 제1호, 2013년 1월 (JBE Vol. 18, No. 1, January 2013)

http://dx.doi.org/10.5909/JBE.2013.18.1.115

ISSN 2287-9137 (Online) ISSN 1226-7953 (Print)

\title{
$\mathrm{DMB} \mathrm{AF}$ 기반 3D 콘텐츠의 MPEG-DASH 서비스
}

\author{
김 용 한 ${ }^{\mathrm{a}}{ }^{\ddagger}$, 박 민 규 ${ }^{\mathrm{a}}$
}

\section{MPEG-DASH Services for 3D Contents Based on DMB AF}

\author{
Yong Han $\mathrm{Kim}^{\mathrm{a})^{\ddagger}}$ and Minkyu Park ${ }^{\mathrm{a})}$
}

요 약

지상파 $\mathrm{DMB}$ 콘텐츠를 위한 국제 표준 파일 포맷인 $\mathrm{DMB} \mathrm{AF}$ (Digital Multimedia Broadcasting Application Format) 표준을 확장하 여 2D 비디오와 2D 대화형 서비스 데이터, 즉 MPEG-4 BIFS(Binary Format for Scene) 데이터뿐만 아니라 스테레오스코픽 비디오와 스 테레오스코픽 $\mathrm{BIFS}$ 데이터를 함께 담아 $2 \mathrm{D} / 3 \mathrm{D}$ 비디오 및 $2 \mathrm{D} / 3 \mathrm{D}$ BIFS 프레젠테이션이 시간적으로 혼용될 수 있게 하는 방식이 최근 제 안된 바 있다. 본 논문에서는 이렇게 확장된 $\mathrm{DMB} \mathrm{AF}$ 형식의 파일로 주어진 3D 콘텐츠를 MPEG-DASH(Dynamic Adaptive Streaming over HTTP) 표준을 이용하여 스트리밍하는 서비스를 개발하고 이에 해당하는 클라이언트 소프트웨어를 구현하여 이 서비스를 검증하였다.

\section{Abstract}

Recently an extension to DMB AF (Digital Multimedia Broadcasting Application Format) standard has been proposed in such a way that the extended DMB AF can include stereoscopic video and stereoscopic images for interactive service data, i.e., MPEG-4 BIFS (Binary Format for Scene) data, in addition to the existing 2D video and 2D images for BIFS services. In this paper we developed a service that provides the streaming of 3D contents in DMB AF by using MPEG-DASH (Dynamic Adaptive Streaming over HTTP) standard and validated it by implementing the client software.

Keywords: MPEG-DASH, multimedia streaming, 3D DMB, DMB AF, stereoscopic video

\section{I. 서 론}

지상파 $\mathrm{DMB}$ 콘텐츠를 위한 국제 표준 파일 포맷인

a) 서울시립대학교(The University of Seoul)

₹ Corresponding Author : 김용한 (Yong Han Kim) E-mail: yhkim@uos.ac.kr

Tel: +82-2-2210-2762 Fax: +82-2-2249-6802 ※ 이 논문은 2011년도 서울시립대학교 연구년교수 연구비에 의하여 연구 되었음.

※ 본 논문 작성을 위해 $3 \mathrm{D}$ 시험 영상을 제공해 주신 한국전자통신연구원 측에 감사를 드립니다.

Manuscript received January 9, 2013. Revised January 18, 2013. Accepted January 18, 2013.
DMB AF(Digital Multimedia Broadcasting Application Format) 표준 ${ }^{[1]-[3]}$ 을 확장하여 $2 \mathrm{D}$ 비디오와 2D 대화형 서비 스 데이터, 즉 MPEG-4 BIFS(Binary Format for Scene) 데 이터뿐만 아니라 스테레오스코픽 비디오와 스테레오스코픽 $\mathrm{BIFS}$ 데이터를 함께 담아 $2 \mathrm{D} / 3 \mathrm{D}$ 비디오 및 2D/3D BIFS 프레젠테이션이 시간적으로 혼용될 수 있게 하는 방식이 최 근 제안된 바 있다 ${ }^{[4],[5]}$. 본 논문에서는 이렇게 확장된 $\mathrm{DMB}$ $\mathrm{AF}$ 형식의 파일로 주어진 3D 콘텐츠를 MPEG-DASH (Dynamic Adaptive Streaming over HTTP) 표준 ${ }^{[6]}$ 을 이용하여 스트리밍하는 서비스를 개발하고 이에 해당하는 클라이언 
트 소프트웨어를 구현하여 이 서비스를 검증하였다.

MPEG-DASH는 미디어 콘텐츠 파일을 여러 미디어 조 각(media segment) 파일로 분할하여 HTTP를 이용하여 클 라이언트로 전달하는 미디어 스트리밍 방식이다. 서버는 일반적인 HTTP 서버와 동일하며, 같은 콘텐츠를 여러 가 지 비트율로 압축한 전체 파일들을 같은 형태로 분할한 미 디어 조각들을 제공한다. 클라이언트는 네트워크 상태를 수시로 측정하고 이에 맞는 비트율로 압축된 파일로부터 얻어진 미디어 조각을 서버로부터 순차적으로 다운로드하 여 미디어를 재현한다. 예를 들어, 두 가지 다른 비트율로 압축된 미디어 파일들로부터 분할된 미디어 조각들을 서버 가 제공한다고 할 때, 네트워크 상태가 좋으면 상대적으로 높은 비트율의 미디어 조각을 다운로드하고, 그렇지 않으 면 낮은 비트율의 미디어 조각을 다운로드한다. 다음 미디 어 조각을 다운로드하기 전에, 네트워크의 상태를 검사하 고 그 결과에 따라 서로 다른 비트율의 미디어 조각 중 하나 를 적절히 선택하여 다운로드한다. 클라이언트에서 서로 다른 비트율의 미디어 조각을 순차적으로 이어서 재현하면, 각 미디어 조각에 해당하는 구간에서 비트율만 달라지고 즉, 화질만 달라질 뿐 미디어의 내용은 누락되거나 중복됨 이 없이 재현되도록 미디어 조각들을 분할하여 서버에 저 장해 둔다. HTTP를 사용하는 웹 서비스가 인터넷에서 가 장 중요한 서비스이기 때문에, 인터넷은 HTTP에 최적화되 어 있다. 따라서 웹 서비스를 위한 파일들이 여러 인터넷 중간 개체들의 캐시(cache)에 저장되었다가 클라이언트로 제공되듯이, MPEG-DASH에 의한 미디어 조각 파일들도 같은 과정으로 클라이언트로 제공된다. 그 결과 $\mathrm{MPEG}-$ $\mathrm{DASH}$ 에 의해 미디어를 스트리밍할 경우, RTP 스트리밍 서비스와는 달리, 방화벽(firewall)을 넘어 스트리밍 서비스 를 제공할 수 있으며, 클라이언트 수가 증가됨에 따라 비례 적으로 미디어 서버를 증설하지 않아도 된다. MPEG$\mathrm{DASH}$ 서비스에 접근하기 위해서 클라이언트는 최초에 MPD(Media Presentation Description)라 불리는 메타데이 터 파일을 다운로드하여야 한다. MPD에는 어떤 비트율의 미디어 조각들을 서버가 제공하는지, 그리고 각 미디어 조 각들의 URL 등의 기본 정보가 들어 있다.

MPEG-DASH 표준에 의하면, 미디어 조각으로 분할하기
전의 파일 포맷으로 MPEG-2 TS(Transport Stream) 표준 ${ }^{[7]}$ 에 의한 MPEG-2 TS와 ISO 기본 미디어 파일 포맷(Base Media File Format, BMFF) ${ }^{[8]}$ 에 의한 ISO BMFF를 지원한 다. 따라서 하나의 MPEG-DASH 서비스는 MPEG-2 TS 파 일로부터 얻어진 일련의 미디어 조각들로 구성되거나 ISO $\mathrm{BMFF}$ 파일로부터 얻어진 일련의 미디어 조각들로 구성된다.

$\mathrm{DMB} \mathrm{AF}$ 는 ISO BMFF, MP4 파일 포맷 과 $\mathrm{AVC}$ 파일 포맷 ${ }^{[10]}$ 등을 함께 사용하고 있으나, 그 구조는 기본적으로 ISO $\mathrm{BMFF}$ 을 따르고 있기 때문에 MPEG-DASH에 의해 스트리밍 될 수 있도록 미디어 조각으로 분리하는 것이 가능하다.

[4]과 [5]에서 제안된 $3 \mathrm{D}$ 콘텐츠를 지원하는 $\mathrm{DMB} \mathrm{AF}$ (이후 이를 $3 \mathrm{D} \mathrm{DMB} \mathrm{AF}$ 라 부르기로 함)는 $3 \mathrm{D}$ 콘텐츠로서 $2 \mathrm{D}$ 비디오에 $3 \mathrm{D}$ 이미지를 $\mathrm{BIFS}$ 를 사용하여 오버레이한 콘 텐츠와 $\mathrm{BIFS}$ 에 의한 이미지가 오버레이되지 않은 $3 \mathrm{D}$ 비디 오의 두 가지 형태의 $3 \mathrm{D}$ 콘텐츠를 지원한다. 여기서 '3D' 라 함은 양안식 스테레오스코픽 비디오를 의미한다. 또 $3 \mathrm{D}$ $\mathrm{DMB} \mathrm{AF}$ 는 시구간에 따라 이러한 $3 \mathrm{D}$ 콘텐츠 형식들과 $2 \mathrm{D}$ 콘텐츠 형식들 중 한 가지를 선택하여 사용하는 시간적 혼 용'을 가능하게 한다.

본 논문에서는 전체 구간의 내용으로서 $\mathrm{BIFS}$ 에 의한 이 미지가 오버레이되지 않은 $3 \mathrm{D}$ 비디오를 담은 $3 \mathrm{D} \mathrm{DMB} \mathrm{AF}$ 파일을 대상으로 MPEG-DASH에 의한 스트리밍 방식을 제안하고, 이를 지원하는 클라이언트 SW 개발하였으며, 이 러한 $3 \mathrm{D} \mathrm{DMB} \mathrm{AF}$ 로부터 얻어진 미디어 조각들을 제공하 는 HTTP 서버로부터 스트리밍을 받아 클라이언트로 재현 함으로써 제안된 방식을 검증하였다.

본 논문의 구성은 다음과 같다. II장에서는 $3 \mathrm{D} \mathrm{DMB} \mathrm{AF}$ 콘텐츠를 MPEG-DASH로 스트리밍하는 방식에 대해 설명 하며, III장에서는 $3 \mathrm{D} \mathrm{DMB} \mathrm{AF}$ 를 지원하는 클라이언트 구 현 및 시험 미디어 조각 파일 제작에 대해 설명하고 이들을 활용한 방식 검증 결과를 제시하였다. 마지막으로 IV장에 서는 결론을 제시하였다.

\section{3D DMB AF 콘텐츠를 MPEG-DASH로 스트리밍하는 방식}

양안식 스테레오스코픽 비디오를 제공하는 서비스와 관 
련된 지상파 $\mathrm{DMB}$ 표준 ${ }^{[1]-[12]}$ 에 의하면, 좌안 영상과 우안 영상을 배치하는 방법을 composition_type으로 시그널링하 는데, 기본 포맷, 선택사항 포맷, 화면분할 포맷 등의 세 가 지 방법에 대해 각기 composition_type 1, 2, 3이라 부르고 있다. 기본 포맷에서는 좌우안 영상의 해상도가 동일하며, 선택사항 포맷에서는 좌우안 영상 중 한 영상의 가로 해상 도가 다른 영상의 절반이며, 화면분할 포맷에서는 좌우안 영상 모두 원래의 해상도의 절반으로서 이를 옆으로 붙여 하나의 화면인 것처럼 전송하도록 하였다. 화면분할 포맷 은 병렬배치(side-by-side) 포맷이라고도 불린다.

$3 \mathrm{D} \mathrm{DMB} \mathrm{AF}$ 에서는 상기 세 가지 composition_type을 모 두 지원한다. composition_type이 1 또는 2 인 경우에는 좌 우안 영상을 각기 서로 다른 트랙(track)으로 저장하며, 3 인 경우에는 하나의 트랙으로 저장한다.

MPEG-DASH로 3D DMB AF 형식의 콘텐츠를 서비스 하려면, composition_type이 1 또는 2 인 경우에는 하나의 미디어 조각에 좌우안 영상의 moof 박스(box)와 이에 상응 하는 mdat 박스를 함께 넣거나 두 개의 미디어 조각에 각기 좌안 또는 우안 영상의 moof 박스와 이에 상응하는 mdat 박스를 분리하여 넣을 수 있다. 좌우안 영상을 두 개의 미디 어 조각에 분리하여 넣으면, $2 \mathrm{D}$ 서비스를 병행하여 제공할 때에 서버의 저장 공간을 줄일 수 있는 장점이 있다. 이는 두 가지 측면에서 그 이유를 찾을 수 있다. 같은 내용의 비 디오에 대해 여러 가지 다른 비트율로 압축된 미디어 조각 을 만들어 MPEG-DASH 서버에 저장하므로, 좌우안 영상 이 하나의 미디어 조각에 함께 들어 있는 경우에는, 좌우안 영상 중 한 영상의 비트율만 다를 경우에도 별도의 미디어 조각으로 저장해야 하기 때문에 서버 저장 공간을 비효율 적으로 사용하게 된다. 예를 들어 좌안 영상을 $500 \mathrm{kbps}$, 우안 영상을 $500 \mathrm{kbps}$ 로 압축하여 좌우안 영상을 하나의 미디어 조각에 넣어 MPEG-DASH 서버에 저장하고, 같은 내용의 비디오에 대해 낮은 비트율의 미디어 조각을 제공 하기 위해, 좌안 영상은 동일한 $500 \mathrm{kbps}$ 로 우안 영상은 $100 \mathrm{kbps}$ 로 압축하여 하나의 미디어 조각에 넣어 MPEG-DASH 서버에 저장하였다고 할 때, 같은 내용의 비 디오에 대해 $500 \mathrm{kbps}$ 로 압축된 좌안 영상이 중복으로 MPEG-DASH 서버에 저장되므로 서버 저장 공간을 비효
율적으로 사용하게 된다. 또 다른 측면에서는, composition_type이 1 인 경우에는 좌우안 영상 중 하나만 클라이언 트로 제공하여 2D 서비스를 제공할 수 있고, composition_type이 2인 경우에는 좌우안 영상 중 해상도가 큰 영상 만 클라이언트로 제공하여 2D 서비스를 제공할 수 있으므 로, 별도의 $2 \mathrm{D}$ 서비스에 사용하는 미디어 조각을 $\mathrm{MPEG}-$ $\mathrm{DASH}$ 서버에 저장하지 않더라도 $3 \mathrm{D}$ 서비스를 위한 좌안 영상이나 우안 영상 미디어 조각들을 $2 \mathrm{D}$ 서비스를 위해 공 유할 수 있기 때문에 서버 저장 공간을 효율적으로 사용할 수 있다.

본 논문에서는 composition_type이 1 또는 2 인 경우 좌우 안 영상을 두 개의 미디어 조각에 분리하여 넣는 방식을 사용하여 실험하였다. composition_type이 3인 경우에는 좌우안 영상을 담은 화면을 하나의 화면인 것처럼 전송하 므로 좌우안 영상을 담은 비디오를 하나의 moof 박스와 이 에 상응하는 mdat 박스에 넣어 하나의 미디어 조각으로 구 성하였다.

오디오의 경우 이를 담은 moof 박스와 이에 상응하는 mdat 박스를 비디오와 함께 하나의 미디어 조각에 넣거나 아니면 별도의 미디어 조각에 넣을 수 있다. 오디오는 비디 오에 비해 상대적으로 비트율이 현저히 낮으므로, 여러 가 지 비트율로 압축된 오디오 미디어 조각을 제공하더라도 네트워크 상태에 적응하는 효과가 미미하다. 따라서 보통 오디오의 경우에는 한 가지 비트율로 압축한다. 만약 오디 오를 비디오와 함께 한 미디어 조각에 넣게 되면, 서로 다른 비트율로 압축된 비디오를 갖는 미디어 조각에 모두 같은 오디오 moof 박스와 이에 상응하는 mdat 박스를 넣어야 하 므로, 서버 저장 공간을 비효율적으로 사용하게 된다. 본 논문에서는 오디오를 하나의 비트율로 압축하여 별도의 미 디어 조각으로 구성하였다.

\section{MPEG-DASH 클라이언트 구현 및 시험 미디어 조각 제작}

본 논문에서는 $3 \mathrm{D} \mathrm{DMB} \mathrm{AF}$ 플레이어 소프트웨어 ${ }^{[5]}$ 를 확장하여 MPEG-DASH 클라이언트를 구현하였다. 플랫폼 
은 윈도우 XP 운영체제이며, $\mathrm{C}++$ 로 다중 쓰레드(thread)를 사용하여 구현하였다. 개발된 MPEG-DASH는 PC 상에서 수행되었고, 실험실 내 또는 외부 HTTP 서버로부터 스트 리밍을 받아 그 결과를 패럴랙스 배리어(parallax-barrier) 방식의 스테레오스코픽 디스플레이에 표시하도록 하였다. 비디오 압축 방식으로는 H.264/AVC, 오디오 압축 방식으 로는 MPEG-4 BSAC을 사용하였다.

그림 1은 본 논문에서 개발된 MPEG-DASH 클라이언트 의 구조와 동작 순서를 보여준다. MPEG-DASH 클라이언 트는 MPD를 분석하는 XML 파서와 MPD 분석부, 미디어 조각들을 적응적으로 다운로드하여 각 미디어 트랙에 해당 하는 미디어 데이터를 제공하는 트랙 제어부, 각 트랙에 해 당하는 미디어 데이터를 읽어 들여 이를 복호하는 $\mathrm{AV}$ 복호 부 그리고 복호된 데이터를 받아 비디오와 오디오를 재현
하는 $\mathrm{AV}$ 재생부로 구성된다.

다운로드된 MPEG-DASH 클라이언트는 최초에 그림 1 의 (1)의 과정에서 MPEG-DASH 서버 역할을 하는 HTTP 서버로부터 MPD 파일을 다운로드한다. (2)의 과정에서 $\mathrm{MPD}$ 파일이 XML로 작성되어 있으므로 XML 문서를 파 싱한 후, 그 내용을 분석하여 초기화 조각(Initialization Segment, IS)의 URL을 알아내고, (3)의 과정에서 IS를 다운 로드한다. (4)의 과정에서 $\mathrm{MPD}$ 를 분석한 결과와 $\mathrm{IS}$ 를 분석 한 결과를 이용하여 트랙 제어부와 $\mathrm{AV}$ 복호부를 초기화한 다. (5)의 과정에서 트랙 제어부에서는 네트워크 상태에 적 응적으로 미디어 조각(Media Segment, MS)들을 순차적으 로 다운로드하여 각 미디어별로 트랙 메모리에 저장한다. (6)의 과정에서 $\mathrm{AV}$ 복호부 내의 비디오 복호부 또는 오디오 복호부는 트랙 리더를 통해 트랙 제어부의 트랙 메모리로

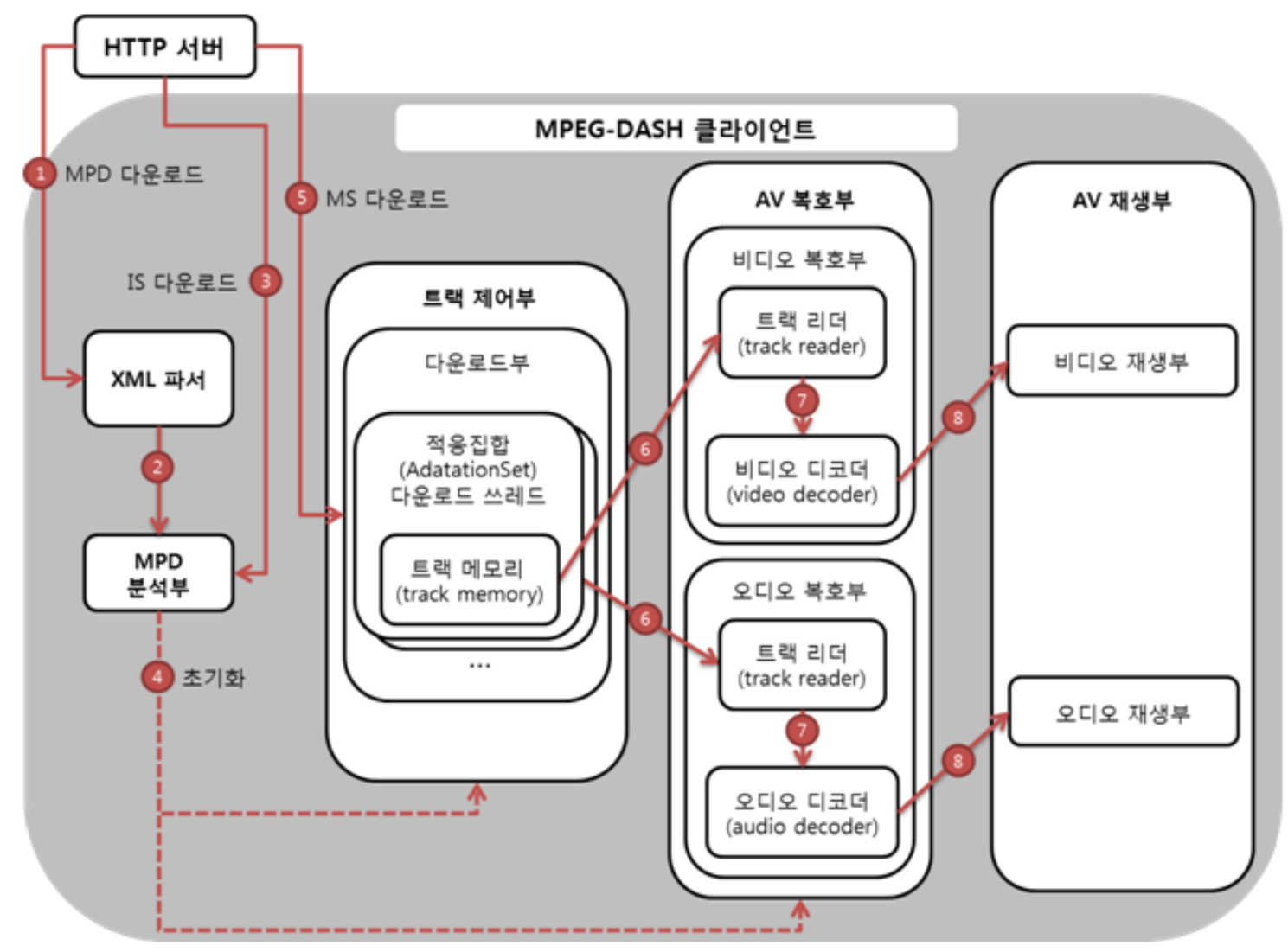

그림 1. 개발된 MPEG-DASH 클라이언트 소프트웨어의 구조 및 동작 순서도

Fig. 1. The architecture and functional flow of the developed MPEG-DASH client software 
부터 미디어 데이터를 읽어와 (7)의 과정에서 비디오 복호 기 또는 오디오 복호기로 복호한다. 8)의 과정에서, 각 미디 어 복호기에서 복호된 결과는 $\mathrm{AV}$ 재생부로 넘겨지고, $\mathrm{AV}$ 재생부는 비디오와 오디오를 재현한다.

시험 미디어 조각 파일을 제작하기 위해 원영상으로는 한국전자통신연구원이 제공한 ‘금강산' 비디오 시퀀스를 사용하였다. ‘금강산' 비디오 시퀀스는 컴퓨터 그래픽스에 의해 합성된 $3 \mathrm{D}$ 비디오 콘텐츠를 담고 있으며, 공간해상도 는 $320 \times 240$ 화소이고, 초당 30 프레임의 순차주사 비디오 시퀀스이다.

composition_type $=1,2,3$ 모두에 대해 각기 해당하는 MPD 파일과 초기화 조각, 그리고 미디어 조각 파일들을 제작하였다. composition_type이 1 또는 2 인 경우, 좌우안 영상을 별도의 미디어 조각으로 구성하였고, composition_type이 3 인 경우에는 좌우안 영상을 하나의 미디어 조 각으로 구성하였다. composition type $=1,2,3$ 모두에 대해 총 재생 길이는 180 초이며, 하나의 미디어 조각은 5 초에 해당하도록 하였 다. 따라서 각 미디어 데이터는 36 개의 미디어 조각으로 구성하였다. 또 하나의 미디어 조각은 5 개의 moof 박스와 그에 상응하는 mdat 박스로 구성하였다. 따라서 한 moof 박스는 1 초의 재생 시간에 상응한다. H.264/AVC로 비디 오를 압축할 때, 한 GOP(Group Of Pictures)를 15 프레임으 로 하여, 하나의 moof 박스는 2 개의 비디오 $\mathrm{GOP}$ 에 대응되 도록 하였다. 오디오는 각 비디오 moof 박스에 해당하는 분량의 내용을 하나의 moof 박스로 작성하였고, 비디오와 마찬가지로 5 개의 moof 박스와 그에 상응하는 mdat 박스 들을 묶어 하나의 미디어 조각을 구성하였다. 하나의 미디 어 조각 안에 하나의 moof 박스와 그에 상응하는 mdat 박 스를 넣는 것이 가장 간단한 구성이다. 그러나 실제로 원재 료에 해당하는 $3 \mathrm{D} \mathrm{DMB} \mathrm{AF}$ 파일은 MPEG-DASH에서 사 용할 미디어 조각의 크기와 무관하게 이미 제작되어 있는

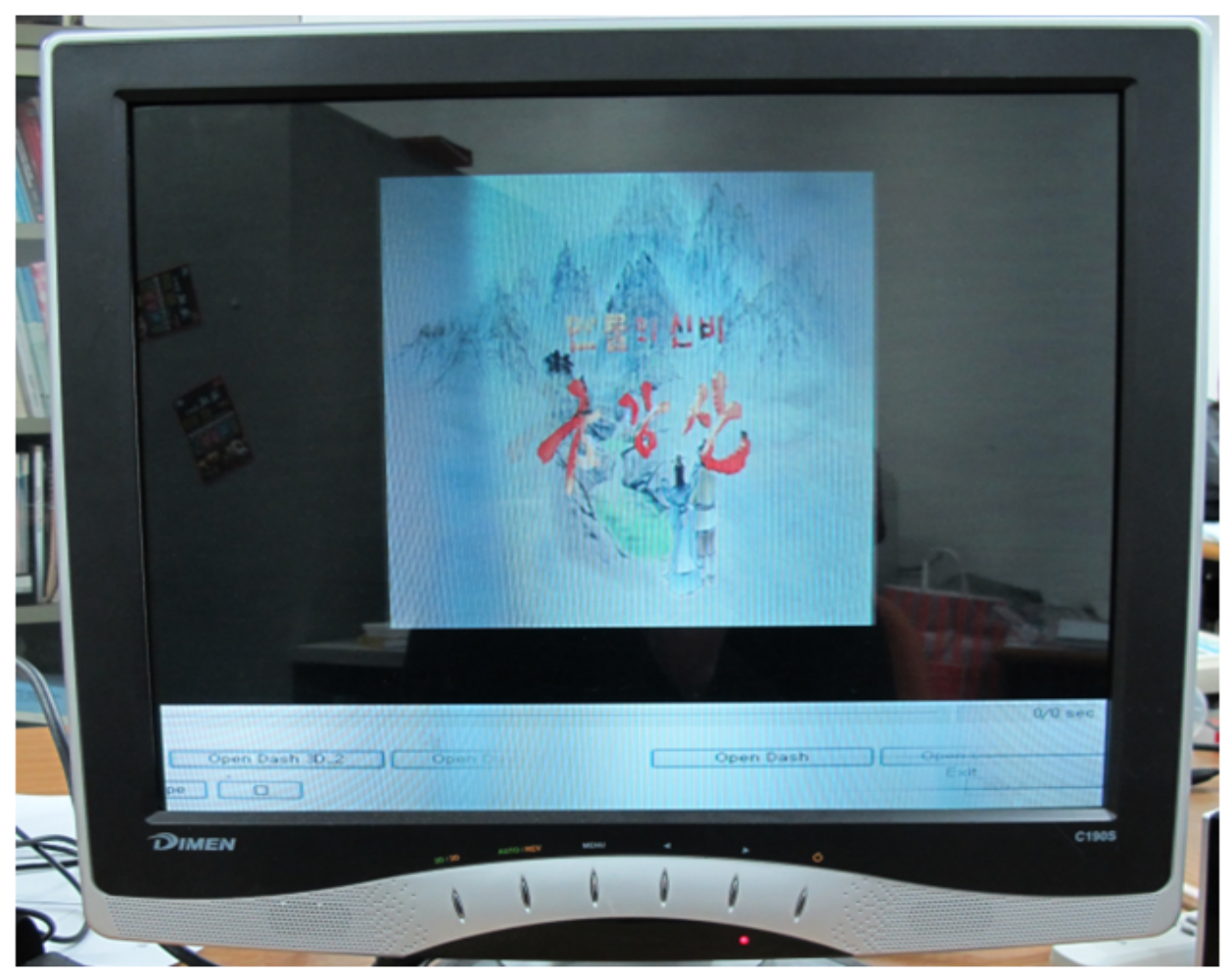

그림 2. 개발된 MPEG-DASH 클라이언트의 스테레오스코픽 디스플레이 출력 결과

Fig. 2. A stereoscopic display output result of the developed MPEG-DASH client software 
경우도 있기 때문에, 필요에 따라 한 미디어 조각에 여러 개의 moof 박스와 그에 상응하는 mdat 박스를 넣을 경우도 있다. 본 논문에서 상기와 같이 미디어 조각을 구성한 이유 는 여러 moof 박스들과 그에 상응하는 mdat 박스들로 구성 된 미디어 조각에 대해서도 본 논문에서 구현한 클라이언 트가 잘 동작함을 검증하고자 하였기 때문이다. 이러한 고 려 외에 실험에서 사용한 구체적인 숫자들은 임의적으로 선택하였다.

미디어 조각에 해당하는 재생 시간의 크기는 초기 지연 시간과 네트워크 상태에 대한 적응 속도를 결정하므로 응 용 분야의 요구사항에 맞게 이를 결정하여야 한다. 본 논문 에서는 임의로 5 초를 사용하였다.

실험에 사용한 비트율은 비디오의 경우 미디어 트랙별로 $500 \mathrm{kbps}$ 와 $256 \mathrm{kbps}$ 의 두 가지이며, 오디오의 경우 128 $\mathrm{kbps}$ 한 가지이다. 서로 다른 비트율의 수와 그 구체적인 비트율, 그리고 네트워크 상태에 적응하는 알고리듬은 실 제 응용 서비스의 요구사항에 맞춰야 하므로, 본 논문에서 는 임의적으로 결정하여 사용하였고, 기능적 검증을 위주 로 시험하였다.

개발된 MPEG-DASH 클라언트 소프트웨어를 사용하여 HTTP 서버로부터 MPEG-DASH 파일들을 다운로드하여 시험한 결과, 모든 composition_type에 대해 MPEG-DASH 클라언트가 원래의 $3 \mathrm{D} \mathrm{DMB}$ 파일에 담겨있던 콘텐츠를 $3 \mathrm{D}$ 로 출력함을 확인할 수 있었다. 그림 2는 패럴랙스 배리 어 타입의 스테레오스코픽 디스플레이를 이용한, composition_type이 2인 경우의 재생화면을 보여준다.

\section{IV. 결 론}

본 논문에서는 지상파 $\mathrm{DMB}$ 를 위한 $3 \mathrm{D}$ 콘텐츠를 담은 $\mathrm{DMB} \mathrm{AF}$ 파일 포맷의 원 데이터로부터 MPEG-DASH 파 일들을 생성하여 HTTP 서버에 저장하고 이를 MPEG$\mathrm{DASH}$ 클라이언트로 인터넷을 통해 다운로드 받아 재생하
는 서비스에 필요한 기본적인 기술들을 개발하고 이를 검 증하였다. 실험에 사용한 세부 파라미터와 네트워크 상태 에 적응하는 알고리듬은 임의적인 것이므로, 향후 이 기술 을 특정 서비스에 적용할 때, 그 요구사항에 따라 조정하여 야 할 것이다.

\section{참 고 문 헌}

[1] ISO/IEC 23000-9:2008, Information technology - Multimedia application format (MPEG-A) - Part 9: Digital Multimedia Broadcasting application format, First Edition, 2008.08.15.

[2] ISO/IEC 23000-9:2008/AMD1, Information technology ? Multimedia application format (MPEG-A) - Part 9: Digital Multimedia Broadcasting application format, AMENDMENT1: Conformance and Reference Software.

[3] HourariSabirin, Munchurl Kim, Hui Yong Kim, Han Kyu Lee, Minkyu Park, and Yong Han Kim, "DMB Application Format for Mobile Multimedia Services", IEEE Multimedia, Vol. 19, No. 2, pp. 38-47, April-June 2012.

[4] Yong Han Kim et al., "A Method to Support Stereoscopic Video in DMB-AF File Format", Proceedings of 2010 Korean Society of Broadcast Engineers Autumn Conference, Paper 9-1, 2010.11.13. (In Korean)

[5] Yong Han Kim and Minkyu Park, "A Development of DMB-AF Player Supporting 3D Video Contents", Journal of Broadcast Engineering, Vol. 16, No. 3, pp. 542-551, May 2011. (In Korean)

[6] ISO/IEC 23009-1:2012, Information technology - Dynamic adaptive streaming over HTTP (DASH) - Part 1: Media presentation description andsegment formats, First Edition, 2012.04.01.

[7] ISO/IEC 13818-1:2007, Information technology - Generic coding of moving pictures and associated audio information: Systems, Third Edition, 2007.10.15.

[8] ISO/IEC 14496-12:3rd Edition, Information technology - Coding of audio-visual objects - Part 12: ISO base media file format.

[9] ISO/IEC 14496-14:2003, Information technology - Coding of audio-visual objects - Part 14: MP4 file format.

[10] ISO/IEC 14496-15:2004, Information technology - Coding of audio-visual objects - Part 15: Advanced Video Coding (AVC) file format.

[11] TTAK.KO-07.0064, Digital Multimedia Broadcasting (DMB) Video-Associated Stereoscopic Data Service, www.tta.or.kr, 2008.12.19.

[12] TTAK.KO-07.0077, Terrestrial Digital Multimedia Broadcasting (DMB) Non-Realtime Stereoscopic Services, www.tta.or.kr, 2010.06.16. 


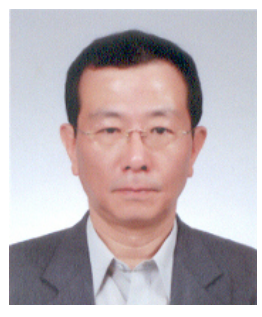

\section{김 용 한}

- 1982년 2월 : 서울대학교 공과대학 제어계측공학과 졸업 (공학사)

- 1984년 2월 : 서울대학교 대학원 제어계측공학과 졸업 (공학석사)

- 1990년 12월 : 미국 렌슬리어공대(Rensselaer Polytechnic Institute) 전기및컴퓨터공학과 졸업 (Ph.D.)

- 1984년 3월 1996년 3월 : 한국전자통신연구원 책임연구원(최종)

- 1991년 10월 1992년 9월 : 일본 NTT 휴먼인터페이스연구소 객원연구원

- 1996년 3월 현재 : 서울시립대학교 공과대학 전자전기컴퓨터공학부 교수

- 2002년 5월 현재 : 차세대방송표준포럼 모바일방송분과위원회(구 DMB분과위원회) 위원장

- 주관심분야 : 영상압축, 디지털방송, 모바일방송, 멀티미디어 시스템, MPEG

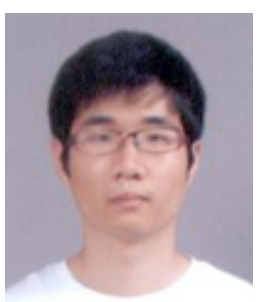

\section{박 민 규}

- 2010년 2월 : 서울시립대학교 공과대학 전자전기컴퓨터공학부 졸업 (공학사)

- 2012년 2월 : 서울시립대학교 대학원 전자전기컴퓨터공학과 졸업 (공학석사)

- 2012년 3월 현재 : 서울시립대학교 대학원 전자전기컴퓨터공학과 박사과정 재학 중

- 주관심분야 : 모바일방송, MPEG, 멀티미디어 시스템 